\title{
THE ACHIEVEMENT OF ENGLISH LANGUAGE CURRICULA FOR SECONDARY STAGE FROM THE PERSPECTIVES OF EFL TEACHERS AND SUPERVISORS IN JORDAN
}

\author{
Mohammad Ahmad Bani Amer, Majid Mohammad Al-Khataybeh \\ Ministry of Education, Mutah University, Jordan \\ E-mail: baniamer1985@yahoo.com
}

Received: 2021-03-17

Accepted: 2021-05-27

\begin{abstract}
This study aims to investigate whether or not the goals of English language curricula for secondary stage have been achieved from the perspectives of EFL teachers and supervisors in Jordan. The participants were $101 \mathrm{EFL}$ teachers and 8 supervisors in Al_Karak educational directorates of Education during the first semester 2020/2021. The researchers designed a questionnaire consisting of fifty-nine items in four areas: listening, speaking, reading and writing skills, used to collect the data for this study. The findings of this study showed that English language teachers and supervisors were mostly satisfied with the goals of English language curriculum for secondary stage. The means for all the areas according to English language teachers was 3.31 while the means for all the areas according to English language supervisors was 3.27. This implies that English language teachers and supervisors were satisfied with the goals of English language curriculum for secondary stage.
\end{abstract}

Keywords: EFL teachers, English language, curriculum, Jordan, Supervisors.

\section{Introduction}

English is now entrenched in Jordan as the first foreign language. English is the customency language for international communication and for overcoming barriers to the flow of information, goods and people across national boundaries. English is the most language generally associated with international trade and tourism, with higher education and research (Alkaldi, 2011). The end of new syllabuses is to set standards for four areas of English language education: - social communication, access to knowledge, performance, and appreciation of culture and literature and language. The aim of new English language curricula is to graduate a literate person who is competent and confident in using language for both functional and aesthetic purposes.

All English curricula secondary stage are centered on the philosophy of language as the base for communicating, learning and thinking. Secondary school students need to continue instruction and extend guided practice in the skills of oral language for formal and informal speaking situations, including public, small group and personal setting. They should identify and use effective strategies to articulate ideas clearly, precisely, accurately and appropriately. The secondary school English language curricula also strive to involve themselves as deeply as possible in the world beyond the classroom. They provide a solid foundation for effective communication in diverse contexts for multiple purposes and roles 
The Achievement of English Language Curricula for Secondary Stage from the Perspectives of EFL Teachers and Supervisors in Jordan. Mohammad Ahmad Bani Amer, Majid Mohammad Al-Khataybeh

in life-as a life- long learner, a responsible citizen, a concerned parent and a productive worker.

In Jordan, English is learnt as a foreign language, and Jordan English is essentially a performance vanity. To gain better understanding of what this means, one might refer to Kachru's concept of three concentric circles, which represents; the types of spread, the patterns of acquisition and the practical fields which English used through cultures and languages. As an EFL country, Jordan belongs to the third circle, the expending circle where English is used as tool for communication, trade, business, diplomacy, travel and as a medium in higher education (Maley, 2011). The educational system in Jordan has three stages: kindergarten for children (two years) Basic (ten years) and secondary (two years) (M.O.E, 2012 a).

Consequently, the government of Jordan realized the need for teaching English quite early and introduced the English language courses as compulsory subject from the kindergarten stage to secondary stage. The secondary stage is the final plan of general education in Jordan. It is a two years period, following on from the Basic stage. Normally students join secondary stage education between the ages of (16-18) years. This stage is considered the most important period in the general education ladder because students who successfully completed this stage are eligible to join any higher educational institution (M.O.E, 2014). This study aims to determine the extent to which the objectives of the secondary stage English Language curricula are achieved. The curricula under investigation are the curricula of secondary stage that have been adopted in the Jordanian public and private school for the secondary stage.

\section{Literature Review}

Ministry of Education (2012 b) defines evaluation as an activity that takes place through the teaching-learning process. Evaluation process is informed by the curriculum, in turn; it informed the method, techniques and strategies of teaching and learning. Ministry of Education recommends that writing down the educational objectives is the first step in the evaluation process and following the general guidelines is an important step in this process. These guidelines are content must include the four language skills, the weight given to each skill must reflect the weight stated in the curriculum, the techniques used in evaluation must be in harmony with the objectives and the recommended techniques and procedures.

Evaluation researches play different functions in education. These roles include providing basis for decision makers, assessing students' achievement, evaluation curricula, accrediting schools, monitoring expenditure of public funds, and improving educational materials and programs (Cohen, Manion, \& Morrison,2011; Jolly\& Bolitho,2011). Evaluation is an educational need because it indicates how a curriculum can be developed or justified. Curricula have a direct effect on the teaching- learning process. The crucial part in the curriculum is textbooks, and does more than merely grease the wheels of teaching- learning process. At their best, they offered concrete models for desirable schoolroom practice. They act as curriculum models and at their very best; they fulfill an instructor improvement role (McGrath, 2013; Tomlinson, 2013). Mishan\&Timmis (2015) mentioned two key aims for evaluating curricula:

1. Providing proof that can mark theoretic contentions about trends to be pursued in teaching language.

2. A tool to show the appropriateness of nominated approaches or techniques under given conditions and whether they meet the claims made for them. 
None of the aforementioned studies investigated the secondary stage English language curricula. The researchers claim that this is the first study investigating the secondary English language curricula stage. The current study differs from the studies in some aspects; the population, the sample, and the instrument. Some of the previous studies evaluated English textbooks as one of the educational inputs in the learning process. Textbooks were evaluated depending on certain characteristics of good English textbooks from supervisors and teachers' perspectives; other evaluated the achievement of objectives using standardized proficiency tests. The present study attempts exclusively to determine the extent to which objectives of secondary stage English language were achieved as one of the educational outputs in the learning process.

\section{Research Method}

\subsection{Population of the Study}

The population of the study consisted of all teachers in (Al_Karak, Al- Mazar, Ghawer Al_Safi, and Al-Qaser) directorates of education. The total number of the study sample was 101 teachers and 8 supervisors. Questionnaires were sent to all the teachers and supervisors, but only 109 questionnaires returned, 101 from teachers and 8 from supervisors. Table (1) presents the sample distribution.

Table 1:

The population distribution

Teachers

\begin{tabular}{|c|c|c|c|c|c|c|}
\hline \multirow[t]{2}{*}{ Gender } & \multicolumn{5}{|c|}{ Years of teaching } & \multirow[t]{2}{*}{ Total } \\
\hline & $1-5$ & $6-10$ & $11-15$ & $16-20$ & 20 and above & \\
\hline Male & 13 & 5 & 11 & 13 & 9 & 51 \\
\hline Female & 12 & 7 & 9 & 8 & 14 & 50 \\
\hline Total & 13 & 12 & 20 & 21 & 23 & 101 \\
\hline
\end{tabular}

\section{Supervisors}

\begin{tabular}{ccccc}
\hline Gender & \multicolumn{3}{c}{ Years of teaching } & Total \\
\hline Male & $6-10$ & $15-11$ & $16-20$ & \\
Female & 1 & 4 & 1 & 6 \\
Total & - & 2 & - & 2 \\
\hline
\end{tabular}

\subsection{Research Instrument}

After analyzing the goals of English language curricula for secondary stage, listed by the English National Team of the MOE (2016), and after reviewing the related literature; a questionnaire was designed by the researcher to gather the information needed, the questionnaire directed for both teachers and supervisors of English language. The researchers designed a questionnaire of five-Likert type scale items: strongly agree, agree, undecided, disagree, strongly disagree. 
The Achievement of English Language Curricula for Secondary Stage from the Perspectives of EFL Teachers and Supervisors in Jordan. Mohammad Ahmad Bani Amer, Majid Mohammad Al-Khataybeh

\subsection{Procedures of the Study}

The researchers designed an initial draft of the questionnaire of (95) items. The questionnaire was submitted to a group of instructors at Jordanian universities, English teachers and supervisors at the Ministry of Education. They were asked to make amendments: adding, changing, omitting or correcting any items. It was amended in light of their comments where some of the items were omitted while the other items were modified.

Finally, the researchers got their final draft which consisted of (59) items. These items were arranged under four domains entitled :( listening, speaking, reading and writing). The listening domain consisted of (15) items while the speaking domain consisted of (15) items whereas the reading domain consisted of (14) items and writing domain consisted of (15) items.

\subsection{Validity of the Instrument Construct Validity}

It was calculated using the correlation between the item score and the test score the correlation coefficient between item score and the test score was around between $\left(0.406^{* *}\right.$ $-0.789^{* *}$ ) This means that the questionnaire was valid.

\section{Piloting the Study}

Before the implementation of the present study, it was piloted to a (15) secondary stage English language teachers and (2) English language supervisors. In the presence of the researchers, the items were read to the respondents who were required to respond to and give their opinions to such items. When a need for clarification arose by the respondents, the researcher was available foe explanation and clarification. Finally, the questionnaire forms were collected and the researchers responded to the notes and comments suggested by the respondents to modify a few items in the questionnaire.

\section{Reliability of the Instrument}

To find out if the study was reliable the questionnaire was forwarded to a number of participants (15) from the population of teachers and supervisors in the current study. Obtained data were calculated and compared with those first got by the questionnaire in the study. Using SPSS programme and the Cronbach alpha was computed as (.87). The reliability equal (0.87) and its significant at $(\alpha=0.01)$.

Table 2:

Alpha formula of instrument reliability

\begin{tabular}{l|l|l}
\hline Number of Cases & Number of Items & Alpha \\
\hline 41.0 & 59 & .87 \\
\hline
\end{tabular}

\subsection{Data Analysis Methods}

In analyzing the study data, the rating took the method of Likert Scales. Rating scales were numerically coded as1-(strongly agree) has 5 points.2-(agree) has 4 points. 3(undecided) has 3 points.4-(disagree) has 2 points.5-(strongly disagree) has 1 point. 
The researchers used SPSS to examine the study data. The data was exposed to analysis through descriptive statistics the means and the standard deviation of each statement were computed.

\section{Results and Discussion}

\subsection{Results Related to the First Question}

Table 3:

Means and stander deviation for all domains according to English language teachers

\begin{tabular}{lcc} 
Domain & Means & Std. Deviatio \\
\hline Listening skills & 3.29 & .520 \\
Speaking skills & 3.16 & .750 \\
Reading skills & 3.49 & .647 \\
Writing skills & 3.27 & .675 \\
Total & $\mathbf{3 . 3 0 7}$ & .584
\end{tabular}

Table (3) shows that the teachers considered all the domains suitable, where their means were statistically medium. The highest rating was given to the reading domain 3.49 , where the lowest rating was given to the speaking domain 3.16.

\section{Listening Skills}

The listening skills domain included 15 items. The means and standard deviation of each item is shown in table (4).

Table 4:

Means and standard deviation for the listening skills domain according to English language teachers

\begin{tabular}{ccc}
\hline Listening skills & Means & Std. Deviation \\
\hline 1 & 3.44 & .923 \\
2 & 3.59 & .706 \\
3 & 3.41 & .836 \\
4 & 3.41 & .865 \\
5 & 2.90 & 1.020 \\
6 & 2.85 & 1.062 \\
7 & 3.24 & .916 \\
8 & 3.41 & .921 \\
9 & 3.59 & .948 \\
10 & 3.12 & 1.053 \\
11 & 3.10 & 1.020 \\
12 & 3.15 & .963 \\
13 & 3.54 & .778 \\
14 & 3.61 & .703 \\
15 & 3.02 & 1.037 \\
Total & $\mathbf{3 . 2 9 2}$ & .52087 \\
\hline
\end{tabular}

Table (4) shows that the evaluation of the listening domain was medium. The highest mean was (3.61) for item L14.The lowest mean was (2.85) for item L6. Teachers expressed their 
The Achievement of English Language Curricula for Secondary Stage from the Perspectives of EFL Teachers and Supervisors in Jordan. Mohammad Ahmad Bani Amer, Majid Mohammad Al-Khataybeh

satisfaction about the listening goals of English Language curricula for secondary stage. The results indicated a complete consensus on the statement that the listening goals of English Language curricula for secondary stage have been achieved. The mean reached 3.3 and the standard deviation is 5.2 .

\section{Speaking Skills}

The speaking skills domain included 15 items. The means and standard deviation of each item is shown in table (5)

Table 5:

Means and standard deviation for the speaking skills domain according to English language teachers

\begin{tabular}{ccc}
\hline Speaking Skills & Means & Std. Deviation \\
\hline 1 & 3.56 & 1.141 \\
2 & 3.37 & .968 \\
3 & 3.15 & 1.062 \\
4 & 3.02 & 1.084 \\
5 & 3.17 & 1.093 \\
6 & 2.78 & 962. \\
7 & 3.20 & .954 \\
8 & 3.07 & 1.104 \\
9 & 3.12 & 1.053 \\
10 & 3.24 & 1.053 \\
11 & 2.95 & .943 \\
12 & 3.17 & 1.024 \\
13 & 3.22 & 1.116 \\
14 & 3.24 & .988 \\
15 & 3.15 & 1.152 \\
Total & 3.1610 & .75011 \\
\hline
\end{tabular}

Table (5) shows that the evaluation of the speaking skill domain was medium. The highest mean was (3.56) for item S1. The lowest mean was (2.78) for item S6. Teachers expressed their satisfaction about the speaking goals of English language curricula for secondary stage. The results indicated a complete consensus on the statement that the speaking goals of English Language curricula for secondary stage have been achieved. The mean reached 3.2 and the standard deviation is .75

\section{Reading Skills}

The reading skills domain included 14 items. The mean and standard deviation of each item is shown in table (6).

Table 6:

Means and standard deviation for the reading skills domain according to English language teachers

\begin{tabular}{ccc}
\hline Reading Skills & Means & Std. Deviation \\
\hline 1 & 3.78 & .822 \\
2 & 3.66 & .762 \\
3 & 3.61 & 1.022 \\
4 & 3.66 & .882 \\
5 & 3.46 & .869 \\
\hline
\end{tabular}




\begin{tabular}{ccc}
\hline 6 & 3.41 & .741 \\
7 & 3.37 & .915 \\
8 & 3.44 & .896 \\
9 & 3.46 & 1.051 \\
10 & 3.29 & .873 \\
11 & 3.44 & .976 \\
12 & 3.39 & .919 \\
13 & 3.56 & .976 \\
14 & 3.39 & .945 \\
Total & $\mathbf{3 . 4 9 4 8}$ & .64728 \\
\hline
\end{tabular}

Table (6) shows that the evaluation of the reading domain was medium. The highest mean was (3.78) for item R1. The lowest mean was (3.29) for item R10.Teachers expressed their satisfaction about the reading goals of English language curricula for secondary stage. The results indicated a complete consensus on the statement that the reading goals of English language curricula for secondary stage have been achieved. The mean reached 3.4 and the standard deviation is .65

\section{Writing Skills}

The writing skills domain included 14 items. The means and standard deviation of each item is shown in table (7)

Table 7:

Means and standard deviation for the writing skills domain according to English language teachers

\begin{tabular}{ccc}
\hline Writing Skills & Means & Std. Deviation \\
\hline 1 & 3.78 & 1.037 \\
2 & 3.22 & .988 \\
3 & 3.20 & 1.054 \\
4 & 3.12 & 1.077 \\
5 & 3.24 & 1.019 \\
6 & 3.29 & .814 \\
7 & 3.10 & .917 \\
8 & 3.34 & .938 \\
9 & 3.29 & .981 \\
10 & 3.49 & .978 \\
11 & 3.34 & .965 \\
12 & 3.27 & 1.073 \\
13 & 3.17 & .919 \\
14 & 3.27 & 1.119 \\
15 & 3.07 & 1.212 \\
Total & 3.2797 & .67548 \\
\hline
\end{tabular}

Table (7) shows that the evaluation of the writing skill domain was medium. The highest mean was (3.78) for item W1. The lowest mean was (3.07) for item W15.Teachers expressed their satisfaction about the reading goals of English language curricula for secondary stage. The results indicated a complete consensus on the statement that the writing goals of English language curricula for secondary stage have been achieved. The mean reached 3.3 and the standard deviation was .68 
The Achievement of English Language Curricula for Secondary Stage from the Perspectives of EFL Teachers and Supervisors in Jordan. Mohammad Ahmad Bani Amer, Majid Mohammad Al-Khataybeh

\subsection{Results Related to the Second Question}

Table 8:

Means and standard deviation for all domains according to English language supervisors

\begin{tabular}{lcc}
\hline Domain & Means & Std. Deviation \\
\hline Listening skills & 3.36 & .201 \\
Speaking skills & 3.24 & .308 \\
Reading skills & 3.16 & .441 \\
Writing skills & 3.31 & .259 \\
Total & $\mathbf{3 . 2 7}$ & $\mathbf{. 2 1 5}$ \\
\hline
\end{tabular}

Table (8) shows that all the Domain were considered suitable by the supervisors, where their means were statistically medium. The highest rating was given to the Listening Domain, where the lowest rating was given to the Reading Domain.

\section{Listening Skills}

The listening skills domain included 15 items. The means and standard deviation of each item is shown in table (9)

Table 9:

Means and standard deviation for the listening skills domain according to English language supervisors

\begin{tabular}{ccc}
\hline Listening Skills & Means & Std. Deviation \\
\hline 1 & 3.80 & .422 \\
2 & 3.60 & .516 \\
3 & 3.60 & .516 \\
4 & 3.30 & .483 \\
5 & 3.20 & .422 \\
6 & 3.20 & .422 \\
7 & 3.30 & .483 \\
8 & 3.10 & .738 \\
9 & 3.30 & .675 \\
10 & 3.60 & .699 \\
11 & 3.40 & .516 \\
12 & 3.50 & .527 \\
13 & 3.50 & 483. \\
14 & 3.20 & .632 \\
15 & 3.00 & .667 \\
Total & 3.36 & .2017 \\
\hline
\end{tabular}

Table (9) shows that the evaluation of the listening skill was medium. The highest mean was (3.80) for item L1. The lowest mean was (3.0) for item L15.Supervisors expressed their satisfaction about the listening goals of English language curricula for secondary stage. The results indicated a complete consensus on the statement that the listening goals of English language curricula for secondary stage have been achieved. The mean reached 3.4 and the standard deviation was .20. 


\section{Speaking Skills}

The speaking skills domain included 15 items. The means and standard deviation of each item is shown in table (10).

Table 10:

Means and standard deviation for the speaking skills domain according to English language supervisors

\begin{tabular}{ccc}
\hline Speaking Skills & Means & Std. Deviation \\
\hline 1 & 3.60 & .699 \\
2 & 3.30 & .675 \\
3 & 3.10 & .738 \\
4 & 2.90 & .568 \\
5 & 3.10 & .568 \\
6 & 3.00 & .667 \\
7 & 3.40 & .699 \\
8 & 3.50 & .707 \\
9 & 3.50 & .707 \\
10 & 3.30 & .483 \\
11 & 3.10 & .568 \\
12 & 3.20 & .422 \\
13 & 3.10 & .568 \\
14 & 3.30 & .675 \\
15 & 3.30 & .832 \\
Total & 3.2467 & .3080 \\
\hline
\end{tabular}

Table (10) shows that the evaluation of the speaking skill domain was medium. The highest mean was (3.90) for item S1. The lowest mean was (2.90) for item S4.Supervisors expressed their satisfaction about the speaking goals of English language curricula for secondary stage. The results indicated a complete consensus on the statement that the speaking goals of English language curricula for secondary stage have been achieved. The mean reached 3.2 and the standard deviation was .30

\section{Reading Skills}

The reading skills domain included 14 items. The mean and standard deviation of each item is shown in table (11)

Table 11:

Means and standard deviation for the reading skills domain according to English language supervisors

\begin{tabular}{ccc}
\hline Reading Skills & Means & Std. Deviation \\
\hline 1 & 3.30 & .823 \\
2 & 3.30 & .675 \\
3 & 3.30 & .483 \\
4 & 3.50 & .707 \\
5 & 3.10 & .568 \\
6 & 3.20 & .789 \\
7 & 2.90 & .568 \\
8 & 3.30 & .483 \\
9 & 3.20 & .632 \\
\hline
\end{tabular}




\begin{tabular}{ccc}
\hline 10 & 3.20 & .632 \\
11 & 2.90 & .738 \\
12 & 2.90 & .568 \\
13 & 3.10 & .738 \\
14 & 3.10 & .876 \\
Total & $\mathbf{3 . 1 6 4}$ & .4416 \\
\hline
\end{tabular}

Table (11) shows that the evaluation of the reading skill domain was medium. The highest mean was (3.50) for item R4. The lowest mean was (2.90) for item R7, R11, R12.Teachers expressed their satisfaction about the reading goals of English language curricula for secondary stage. The results indicated a complete consensus on the statement that the reading goals of English language curricula for secondary stage have been achieved. The mean reached 3.2 and the standard deviation was .44 .

\section{Writing Skills}

The writing skills domain included 14 items. The means and standard deviation of each item is shown in table (12)

Table 12:

Means and standard deviation for the writing skills domain according to English language supervisors

\begin{tabular}{ccc}
\hline Writing Skills & Means & Std. Deviation \\
\hline 1 & 3.20 & .632 \\
2 & 3.40 & .699 \\
3 & 3.20 & .632 \\
4 & 3.10 & .876 \\
5 & 3.10 & .568 \\
6 & 3.40 & .516 \\
7 & 3.30 & .483 \\
8 & 3.20 & .789 \\
9 & 3.40 & .699 \\
10 & 3.40 & .699 \\
11 & 3.50 & .707 \\
12 & 3.30 & .823 \\
13 & 3.50 & .707 \\
14 & 3.30 & .483 \\
15 & 3.40 & .516 \\
Total & 3.313 & .2592 \\
\hline
\end{tabular}

Table (11) shows that the evaluation of the writing skill domain was medium. The highest mean was (3.50) for item W11 and W13.The lowest mean was (3.10) for item W4 and W5. Supervisors expressed their satisfaction about the reading goals of English language curricula for secondary stage. The results indicate a complete consensus on the statement that the writing goals of English language curricula for secondary stage have been achieved. The mean reached 3.3 and the standard deviation was .26

\subsection{Discussion of the First Question Results}

The findings of question one show that the means scores for the teachers' investigation (listening skill, speaking, reading skill, and writing skill) were medium. The total mean of the 
evaluated domains was (3.31). The highest mean was (3.5) for the reading skill domain, while the lowest was (3.16) for the speaking skill domain.

The results of the study concerning the main strengths of English language curricula for secondary stage indicated that teachers were completely convinced of the achieving of reading skills. They considered that the English language curricula for secondary stage curricula contain meaningful, authentic, and suitable texts.

Curricula provide a variety of meaningful and mechanical exercises and activities to practice language items and skills; they provide communicative exercises and activities that help students carry out their communicative tasks in real life situation. The findings of the study revealed that the teachers agreed on the clarity of the objectives and their gradual level of difficulty, presenting interesting texts, relevance of grammar to the students' needs and interests, selecting and presenting the new vocabularies, provision of cassettes, CDs and utility of teaching aids.

The researchers attribute this to many factors; the time allotted for listening and speaking activities is not sufficient, there is still a gap between theory and practice, most of students use mother tongue, teachers are always giving less chance for language practice, and exams usually depend on memorization and are usually based on grammar, this can be attributed to the fact that the teachers and students do not

Participate in selecting the textbook objectives; the reading texts are meaningful and authentic. However, some writings are difficult for most of the students. This is for the reason that learners are obligatory to write long passages, papers or letters and listening and speaking are appropriate and helpful for the teachers; the exercises are relatively designed properly to suit the students' levels and interests.

\subsection{Discussion of the Second Question Results}

The findings of question two shows that the means scores for the supervisors' investigation (listening skill, speaking, reading skill, and writing skill) were medium. The total mean of the evaluated domains was (3.27). The highest mean was (3.36) for the listening skill domain, while the lowest was (3.16) for the reading skill domain. It is quite clear that the supervisors agreed on the achieving of English language curricula for secondary stage goals in terms of the four skills domains, Such medium evaluative scores may be ascribed the wide awareness of all aspects of the new curricula and to the role they play as trainees when being enrolled in training programs held by the Ministry of education on how to teach the newly developed curricula , and as trainers who took the rest of responsibility to train the teachers in the field on how to precisely deal with the new curricula. The results of the study concerning the main strengths of English language curricula for secondary stage indicated that teachers were completely convinced of the achieving of the four skills.

\section{Conclusion}

The purpose of this study was to investigate whether or not the English language curricula for secondary stage have achieved their goals from the perspectives of EFL teachers and supervisors in Jordan. A survey questionnaire was used in this study to elicit the perspectives of 101 English language and 8 supervisors in (Al_Karak, Al- Mazar, Gahwer Al_Safi, and Al-Qaser) directorates' education of about English language curricula for secondary stage. The questionnaire consisted of 59 items grouped under four main categories: listening domain, speaking domain, reading domain, and writing domain. The listening domain was measured by 15 items. The speaking domain was measured by 15 
The Achievement of English Language Curricula for Secondary Stage from the Perspectives of EFL Teachers and Supervisors in Jordan. Mohammad Ahmad Bani Amer, Majid Mohammad Al-Khataybeh

items. The reading domain was measured by 14 items. The writing domain was measured by 15 items.

Validity and reliability were ensured. Moreover, Cronbach's alpha and descriptive statistics that included the mean scores and standard deviations were computed by using the SPSS program to answer the questions of the study. To guarantee accurate discussion results, the researchers adopted a specific criterion to decide whether the teachers and supervisors' response to the questionnaire in general were considered (low, medium, and high) on the Likert scale.

The results of the study indicated that the secondary English language teachers and supervisor were generally satisfied with the goals of the secondary English language. In particular, the means of the teachers' perspectives was (3.3) whereas the means of the supervisors' perspectives was (3.3). This implied that the teachers and supervisors were completely satisfied with all domains.

\section{References}

Alemi, M. \& Mesbah, Z., (2013). Textbook Evaluation Based on the ACTFL Standards: The Case Study of Top Notch series. The Iranian EFL Journal, 9(1):62-71.

Alkhaldi, A. (2011). Materials Development in Jordan: An Applied Linguistics Challenge. Unpublished PhD Thesis. Leeds Metropolitan University.UK.

Cohen, L., Manion, L. \& Morrison, K. (2011). Research Method in Education. London.

Demir, Y., \& Ertas, A. (2014). A Suggested Eclectic Checklist for ELT Course Book Evaluation. The Reading Matrix, 14(2): 243-252.

Jolly, D. \& Bolitho, R. (2011). A Framework for Materials Writing, in Tomlinson, B. (ed., 2nd edn.). Materials Development in Language Teaching. Cambridge: Cambridge University Press.

Maley, A. (2011). Squaring the Circle - Reconciling Materials as Constraint with Materials as Empowerment, in Tomlinson, B. (Ed.). Materials Development in Language Teaching. Cambridge: Cambridge University Press.

McGrath, I. (2002). Materials Evaluation and Design for Language teaching. Edinburgh: Edinburgh University Press.

McGrath, I. (2013). Teaching Materials and the Roles of EFL/ESL Teachers. London.

Ministry of Education (2016). General Guidelines and Curricula for Basic and Secondary Stages. Prepared by The English Language National Team, Curricula and School Textbooks Administration, Amman, Jordan.

Ministry of Education. (2014). National Education Strategy. Directorate of educational research and development, Jordan.

Ministry of Education. (2012) General Guidelines and Curricula for Basic and Secondary Stages. Prepared by The English Language National Team. Amman, Jordan.

Mishan, F. \& Timmis, I. (2015). Materials Development for TESOL. Edinburgh. Edinburgh University Press.

Tomlinson, B. (2013). Developing Principles Frameworks for Materials Development, in Tomlinson, B. (Ed.). Developing Materials for Language Teaching. London: Continuum. 